\title{
Analisa Perkembangan Jumlah Outlet Kantor Cabang dan Kebutuhan Frontliners di Era Digital Banking (Studi kasus di Bank Syariah Anak Perusahaan dan UUS Bank BUMN di Yogyakarta)
}

\author{
Nur Ellyanawati ER \\ Universitas Islam Indonesia \\ Email : nur.ellyanawati@uii.ac.id
}

\begin{abstract}
ABSTRAK
Penelitian ini bertujuan untuk menganalisa perkembangan jumlah outlet kantor cabang dan kebutuhan frontliners di Era Digital Banking(studi kasus di Bank Syariah Anak Perusahaan dan Unit Usaha Syariah Bank BUMN di Yogyakarta). Hasil penelitian menunjukkan selama tahun 2015 sampai tahun 2018 jumlah outlet Kantor bank syariah di Yogyakarta dan jumlah teller tidak menunjukkan perkembangan tetapi juga tidak ada pengurangan. Sedangkan customer service ada penambahan karena jumlah tenaga marketing bank yang bertambah. Kebutuhan industri perbankan untuk saat ini adalah tenaga pemasar, sedangkan frontliners selama 3 tahun belum ada penambahan kebutuhan tenaga kerja. Sehingga bagi dunia pendidikan bisa menyesuaikan kurikulum pendidikannya agar dapat menyesuaikan kebutuhan industri.
\end{abstract}

Kata kunci : Digital Banking, Bank Syariah, Kantor Cabang Bank, Frontliners.

\begin{abstract}
The research aims to analyze the development of branch offices and the need of frontliner in the digital banking era (case study in subsidiary Syariah Bank and Businees Unit of Syariah Bank in Yogyakarta). The result of the research shows during the research the number of syariah bank outlets reaches the same. The research mentions a need for the position of customer service increases as it is in line with the increasing number of marketing staffs. Frontliner's position still remains the same. Suggestion for those dealing with education field is to adjust its curriculum in order to balance with the need for industry.
\end{abstract}

Key Words: Digital Banking, Bank Syariah, Branch Banking, Frontliners. 


\section{A. Pendahuluan}

Perkembangan teknologi perbankan saat ini menuntut perbankan mampu memanfaatkan peluang era globalisasi dan perkembangan teknologi yang begitu pesat agar bank tersebut tetap bisa mengikuti perkembangan dan persaingan bisnis. Rasionalisasi organisasi untuk mengubah sistem branch banking ke sistem perbankan digital bisa menciptakan turbulensi internal di bank-bank,karena revolusi teknologi digital telah melahirkan keuangan berbasis teknologi atau financial technology (fintech) yang diakui para banker memiliki kegesitan dalam mendekati pasar secara digital.

Faktor teknologi yang berkembang pesat ini mendapat perhatian ekstra dari perbankan, karena adanya tren teknologi ini mengakibatkan interaksi antara nasabah dan bank mulai berkurang. Saat ini nasabah dapat memilih menggunakan fasilitas teknologi untuk bertransaksi seperti atm, cdm, sms banking, mobile banking, ataupun internet banking untuk keperluan transfer/pengiriman uang maupun untuk pembayaran tagihan-tagihan nasabah. Kecepatan dan kemudahan fasilitas teknologi ini membuat nasabah tidak perlu datang ke kantor cabang untuk melakukan transaksi. Mereka lebih memilih fasilitas teknologi dengan pertimbangan kemudahan, kecepatan, dan menghemat waktu. Transformasi untuk menyesuaikan perkembangan teknologi tentu harus dilakukan secara strategis oleh bank-bank.

Menurut Wijaya, Biro Riset BI mencatat sejak Desember 2015 hingga Agustus 2018 jumlah kantor cabang bank milik bank-bank umum di Indonesia ternyata berkurang sejumlah 314 unit atau dari 32,949 menjadi 32.635. ${ }^{1}$ Hal ini disebabkan oleh beberapa hal diantaranya kinerja bisnis perbankan yang sedang mengalami kelesuan sejak tiga tahun terakhir sehingga bank menjadi lebih memilih untuk melakukan efisiensi. Bentuk efisiensi salah satunya adalah dengan menutup kantor cabangnya. Yang patut diantisipasi adalah mengurangi jumlah jaringan kantor yang sudah terlanjur banyak saat dalam kondisi tidak krisis. Hal itu bisa menganggu suasana kerja organisasi karena ada tenaga kerja yang tidak terpakai lantaran tak sesuai dengan kebutuhan organisasi.

Layanan digital banking saat ini yang sedang berkembang menyebabkan adanya pandangan bahwa bank tanpa adanya layanan digital adalah bank

\footnotetext{
${ }^{1}$ Krisna Wijaya, 2018, Digital Banking, Majalah Infobank, Jakarta
} 
tradisional. ${ }^{2}$ Akibatnya bagi bank yang belum mempunyai layanan digital merasa perlu mempunyai layanan digital agar tidak dipersepsikan sebagai bank tradisional. Jika diperhatikan secara seksama apa yang diwujudkan oleh sebuah bank dalam memberikan layanan digital masih mempunyai keterbatasan yaitu jumlah, nilai transaksi, dan frekuensi transaksi yang dapat dilakukan. Dalam praktiknya keberadaan outlet kantor bank tetap dibutuhkan oleh nasabah. Yaitu apabila terjadi permasalahan teknis masih banyak yang mengharuskan nasabah untuk datang ke kantor cabang terdekat.

Digitalisasi perbankan tidak hanya berdampak bagi bank konvensional tetapi juga bisa bagi bank syariah. Bank syariah melakukan perbaikan teknologi untuk mempermudah akses layanan transaksi keuangan nasabahnya. Namun tentunya tiap daerah memiliki kharakter nasabah berbeda-beda. Misalnya Yogyakarta tentu akan berbeda dengan kharakteristik nasabah di Jakarta ataupun Surabaya. Masih ada nasabah yang lebih suka datang ke kantor cabang bank untuk berinteraksi dengan petugas bank atau karena adanya limit batasan transaksi keuangan yang menggunakan layanan digital banking.

Dari uraian di ataslah yang menjadi dasar untuk melakukan penelitian dengan judul "Analisa Perkembangan Jumlah Outlet Kantor Cabang dan Kebutuhan Frontliners di Era Digital Banking.(Studi Kasus di Bank Syariah Anak Perusahaan dan Unit Usaha Syariah Bank BUMN di Yogyakarta).”

\section{Digital Banking}

Sejalan dengan perkembangan teknologi informasi, layanan yang disediakan Bank mengalami evolusi yang mengarah kepada layanan perbankan digital (DigitalBanking). Layanan ini lebih berorientasi kepada pemenuhan kebutuhan nasabahdengan memanfaatkan sepenuhnya teknologi digital melalui perangkat (device) dan aplikasi (software) sebagai delivery channel. Selain itu, layanan perbankan digital dapat diakses kapan saja dan di mana saja, serta meminimalkan interaksi secara langsung dengan pegawai Bank. Hal ini bertujuan juga untuk meningkatkan efisiensi kegiatan operasional dan mutu pelayanan Bank kepada nasabahnya.

${ }^{2}$ Ibid., 
Layanan perbankan digital adalah layanan atau kegiatan perbankan dengan menggunakan sarana elektronik atau digital milik bank, dan/atau melalui digital milik calon nasabah dan/atau nasabah bank, yang dilakukan secara mandiri. ${ }^{3}$ Hal ini memungkinkan calon nasabah dan/atau nasabah bank untuk memperoleh informasi, melakukan komunikasi, registrasi, pembukaan rekening, transaksi perbankan, dan penutupan rekening, termasuk memperoleh informasi lain dan transaksi di luar produk perbankan, antara lain nasihat keuangan (financialadvisory), investasi, transaksi sistem perdagangan berbasis elektronik (e-commerce), dan kebutuhan lainnya dari nasabah bank. Pengembangan strategi bisnis yang mengarah kepada layanan perbankan digital memerlukan infrastruktur yang memadai antara lain manajemen risiko, penyesuaian teknologi informasi, business model, business process, internal control, dan sumber daya manusia.

Dalam penyelenggaraan layanan perbankan digital di Indonesia, sangat penting bagi semua pihak untuk meyakini kehandalan faktor keamanan (security) transaksi layanan perbankan digital guna memperoleh kepercayaan (trust) semua pihak terutama nasabah terhadap layanan perbankan digital tersebut (Fajrian, 2018).

Layanan perbankan digital yang berbasis teknologi informmasi umumnya dikenal sebagai electronic banking (e-banking), layanan ini memudahkan nasabah untuk melaksanakan transaksi keuangan melalui berbagai delivery channelyang disediakan oleh bank. Beberapa layanan digital banking adalah sebagai berikut :Automatic Teller Machine (ATM), Cash Deposit Machine (CDM), Electronic Data Capture (EDC), Internet banking, Short Messaging Service (SMS) Banking,Phone Banking, maupunMobile Banking.Meningkatnya transaksi keuangan nasabah melalui layanan electronic banking channel, berdampak pada penurunan jumlah transaksi keuangan yang dilakukan nasabah melalui ATM dan kantor cabang. Hal ini menunjukkan adanya perubahan perilaku dan kebiasaan nasabah yang mulai mengarah kepada transaksi e-banking melalui perangkat digital yang memberikan kemudahan bagi nasabah.

Beberapa layanan digital banking adalah sebagai berikut: ${ }^{4}$

\section{ATM (Automatic Teller Machine)}

\footnotetext{
${ }^{3}$ Wirjoatmodjo, Kartika, 2018,Transformasi Digital Suatu Keniscayaan, Majalah Infobank, Jakarta ${ }^{4}$ https://sikapiuangmu.ojk.go.id
} 
Mesin ATM dapat digunakan untuk melakukan cek saldo, cek rincian transaksi, penarikan, transfer, pembayaran, dll. Jaringan layanan melalui ATM bisa ATM Bersama, ATM Link, dan ATM Cirrus

2. CDM (Cash Deposit Machine)

Mesin yang dapat digunakan untuk melakukan cek saldo, cek rincian transaksi, penarikan, penyetoran uang, transfer, pembayaran, dll. Selain untuk penyetoran pada mesin ini bisa digunakan untuk melakukan penarikan, sehingga dibanding mesin ATM fitur pada mesin CDM lebih lengkap.

3. EDC (Electronic Data Capture)

Mesin ini bentuknya simple dan fleksibel. Fungsinya adalah sebagai pengganti pembayaran transaksi pembayaran belanja nasabah sehingga tidak lagi menggunakan uang tunai. Jaringan logo pada mesin EDC yaitu mastercarddan co-branding dengan salah 1 bank. Kartu yang bisa dipakai untuk pembayaran belanja adalah debit card maupun credit card milik semua perbankan.

4. SMS (Short Massage System) Banking

SMS Banking adalah layanan transaksi perbankan yang dapat dilakukan nasabah melalui telepon seluler (ponsel) dengan suatu format SMS. Nasabah dapat mengirimkan SMS ke nomor telepon bank atau menggunakan aplikasi yang dipasang bank pada ponsel nasabah.

5. Internet Banking

Nasabah dapat melakukan transaksi perbankan (transaksi finansial dan non finansial) melalui komputer yang terhubung dengan jaringan internet.

6. Phone Banking

Nasabah dapat melakukan transaksi perbankan melalui telepon dimana nasabah menghubungi contact center bank. Bank telah menyediakan tenaga staf khusus yang akan menjalankan transaksi nasabah atau program otomatis yang dapatberinteraksi dengan nasabah (melalui telepon) untuk menjalankan transaksi nasabah.

7. Mobile Banking

Mobile banking adalah layanan perbankan yang juga dapat diakses langsung melalui ponsel seperti sms banking, namun memiliki tingkat kecanggihan yang lebih tinggi. Bank bekerjasama dengan operator seluler, sehingga dalam 
Sim Card (kartu chips seluler) Global for Mobile Communication (GSM) sudah dipasangkan program khusus untuk bisa melakukan transaksi perbankan.

Seiring dengan perkembangan teknologi informasi yang begitu cepat dan perubahan perilaku nasabah, saat ini perbankan mulai meningkatkan layanannya agar nasabah dapat memperoleh berbagai layanan perbankan secara mandiri (selfservice) tanpa harus mendatangi kantor bank. Layanan perbankan secara mandiri antara lain melakukan registrasi, transaksi (tunai, transfer, pembayaran) dan berbagai layanan lainnya, hingga penutupan rekening yang dikenal juga dengan istilah layanan perbankan digital (digital banking). Perkembangan layanan perbankan digital didorong oleh hal-hal sebagai berikut: ${ }^{5}$

1. Adanya perkembangan teknologi informasi yang pesat;

2. Perubahan gaya hidup masyarakat sesuai perkembangan teknologi informasi;

3. Adanya kebutuhan masyarakat terhadap layanan perbankan yang efektif, efisien, dapat diakses dari manapun dan kapanpun, komprehensif, serta mudah;

4. Kompetisi industri perbankan untuk memberikan layanan sesuai dengan kebutuhan masyarakat; dan

5. Kebutuhan perbankan terhadap operasional yang efisien dan terintegrasi.

Perkembangan digital banking yang ini berdampak pada hal-hal berikut ini, yaitu: ${ }^{6}$

1. Banyak ditutupnya kantor cabang bank.

2. Berkurangnya transaksi nasabah melalui teller di bank dan nasabah lebih memilih menggunakan electronic banking (electronic channel).

3. Banyaknya staff frontliners bank yang dikurangi karena transaksi layanan nasabah dilakukan secara mandiri oleh nasabah. Keberadaan di bank banyak yang load pekerjaannya berkurang, sehingga manajemen bank tersebut mengadakan pengurangan pegawai.

\section{Bank Syariah}

\footnotetext{
${ }^{5}$ Otoritas Jasa Keuangan, 2016, Panduan Penyelenggaraan Digital Branch oleh Bank Umum, Jakarta.

${ }^{6}$ Ibid.,
} 
Bank syariah adalah suatu sistem perbankan yang pelaksanaannya berdasarkan hukum Islam (syariah). Pembentukan sistem ini berdasarkan adanya larangan dalam agama Islam untuk meminjamkan atau memungut pinjaman dengan mengenakan bunga pinjaman (riba), serta larangan untuk berinvestasi pada usaha-usaha yang berkategori terlarang (haram). ${ }^{7}$ Perbedaan antara bank syariah dengan bank konvensional adalah sebagai berikut. ${ }^{8}$ Bank syariah : 1) Hanya melakukan investasi yang halal menurut hukum Islam 2) Memakai prinsip bagi hasil, jual beli, dan sewa 3) Berorientasi keuntungan dan falah (kebahagiaan dunia dan akherat sesuai ajaran Islam) 4) Hubungan dengan nasabah dalam bentuk kemitraan 5) penghimpunan dan penyaluran dana sesuai fatwa DPS. Sedangkan Bank Konvensional : 1) Melakukan investasi baik yang halal atau haram menurut hukum Islam 2) Memakai perangkat suku bunga 3) Berorientasi keuntungan 4) Hubungan dengan nasabah dalam bentuk kreditur dan debitur 5) Penghimpunan dan penyaluran dana tidak diatur oleh dewan sejenis.

Sama halnya dengan bank konvensional, bank syariah juga memiliki produk dan layanan serupa seperti bank konvensional. Misalnya produk tabungan, giro, deposito, layanan penyetoran, penarikan uang, kiriman uang, pembayaranpembayaran, bahkan layanan yang menggunakan teknologi yang sekarang sedang berkembang yaitu layanan electronic banking. Layanan electronic banking meliputi atm, cdm, edc, sms banking, phone banking, mobile banking, dan internet banking.

\section{Kantor Cabang Bank}

Kantor Cabang Bank adalah kantor bank yang secara langsung bertanggung jawab kepada kantor pusat bank yang bersangkutan, dengan tempat usaha yang permanen dan alamat kantor yang jelas tempat kantor cabang tersebut melakukan kegiatannya (branch office). Biasanya di kantor cabang bank ini di dalamnya terdapat semua unit yang ada di perbankan, seperti unit layanan, pemasaran, processing, collecting, administrasi, unit sdm dan umum, dan unit keuangan. Untuk perbankan syariah juga memiliki kantor cabang syariah yaitu kantor cabang unit usaha syariah (UUS) yang bertanggung jawab kepada UUS

\footnotetext{
${ }^{7}$ Muhammad Syafii Antonio, 2001, Bank Syariah Dari Teori Ke Praktik, Jakarta, Gema Insani.

${ }^{8}$ Totok Budisantoso \& Sigit Triandaru, 2011, Bank dan Lembaga Keuangan Lain, Edisi 3, Jakarta, Salemba Empat.
} 
yang bersangkutan, dengan alamat tempat usaha yang jelas sesuai dengan lokasi kantor cabang syariah (KCS) tersebut melakukan usahanya, termasuk kantor cabang pembantu syariah dari suatu bank yang berkedudukan di luar negeri.

Bank dalam menjalankan operasional bisnisnya membutuhkan tempat atau kantor untuk melaksanakan aktivitas-aktrvitas bisnis atau usahanya. Kantor pusat menandakan lokasi fungsi terpenting dari suatu organisasi yang dipimpin. Semua kegiatan perencanaan sampai dengan pengawasan terdapat di kantor ini. Setiap perusahaan memiliki suatu kantor pusat dan kantor pusat tidak dapat melakukan kegiatan operasional sebagaimana kantor lainnya, akan tetapi mengendalikan kebijaksanaan kantor pusat terhadap cabang-cabangnya. Kantor pusat bank untuk skala nasional (bank nasional) berada di ibukota sebuah negara. Untuk kantor pusat bank di Indonesia pada umumnya berada di Jakarta. Kantor pusat sebuat bank membawahi kantor cabang bank yang terletak di kota-kota besar, yaitu di tiap-tiap Propinsi atau di tiap-tiap kabupaten/kotamadya. Sedangkan kantor cabang dalam menjalankan operasionalnya juga dibantu oleh kantor cabang pembantu dan kantor kas.

Syariah Channeling Outlet (SCO) adalah kantor bank konvensional yang dapat melayani transaksi perbankan syariah. Bank konvensional yang dimaksud adalah bank induk dari bank syariah. Misalnya BRI dengan BRI Syariah, Bank Mandiri dengan Bank Mandiri Syariah, Bank BNI dengan Bank BNI Syariah, dan Bank BTN dengan Unit Usahanya yaitu Bank BTN Syariah.Namun sebaliknya bank syariah tidak dapat melayani transaksi pembukaan rekening bank konvensional.

\section{Frontliners}

Frontliners adalah petugas atau staff bank yang berada diposisi garis depan dalam melayani kebutuhan nasabah. ${ }^{9}$ Frontliners bank terdiri dari teller, customer service, satpam, dan supervisor layanan. Teller adalah perugas yang melayani setoran, penarikan, kiriman uang, pemindahbukuan atau overbooking, penukaran uang atau yang berkaitan dengan transaksi keuangan nasabah.Customer Service adalah petugas yang melayani nasabah dalam hal menjelaskan produk yang DPK, melayani pembukaan rekening, melayani pemesanan ATM, Internet

\footnotetext{
${ }^{9}$ Moenir, H.A.S.2002, Manajemen Pelayanan Umum di Indonesia, Jakarta, PT Bumi Aksara.
} 
Banking, Mobile Banking, SMS Banking, melayani atau menghandle komplain atau pengaduan nasabah, dan lain sebagainya. Satpam adalah petugas keamanan yang menjaga dan memastikan keadaan aman bagi semua nasabah yang datang di bank dan juga menjaga keamanan asset-aset yang dimiliki perusahaan. Supervisor layanan adalah petugas bank yang memastikan dan mengatur semua staff yang dimilikinya dapat bekerja dengan baik, layanan nasabah dapat berjalan dengan lancar dan nasabah dapat terpenuhi harapannya. Selain itu supervisor juga bertanggung-jawab para staffnya dapat mengaplikasikan ketentuan dari layanan yang telah ditetapkan perusahaan.

\section{Kerangka Pemikiran}



Pendekatan yang digunakan peneliti adalah dengan deskriptif-kualitatif serta data-data pendukung seperti literatur dan sebagainya. Yaitu penelitian yang bertujuan menggambarkan suatu keadaan atau sifat seperti apa adanya. ${ }^{10}$

\footnotetext{
${ }^{10}$ Sugiyono, 2006, Metode Penelitian Kuantitatif Kualitatif dan R\&D, Alfabeta, Bandung.
} 
Penelitian ini dilaksanakan untuk memastikan atau menggambarkan ciri-ciri atau karakteristik dari objek yang diteliti. Sumber data diperoleh dalam penelitian ini melalui sumber data primer dan data sekunder.Data primer yaitu sumber data yang diperoleh secara langsung dari sumber pertama melalui wawancara dan pengamatan langsung kepada kepada pihakkompeten dan dapat memberikan informasi mengenai penelitian ini. Data sekunder yaitu sumber data yang diperoleh dari laporan-laporan yang dikeluarkan dari tahun 2015 sampai dengan 2018, serta literatur pustaka yang berkaitan dengan materi penelitian ini.

Populasi dalam penelitian ini adalah seluruh Bank Syariah di wilayah Yogyakarta. Sedangkan sampel yang diambil adalah seluruh Bank Syariah Anak Perusahaan Bank BUMN dan Bank Syariah Unit Usaha Syariah Bank BUMN yang memiliki Kantor Cabang di Yogyakarta yaitu Bank BNI Syariah Cabang Yogyakarta, Bank BRI Syariah Cabang Yogyakarta, Bank BTN Syariah Cabang Yogyakarta, dan Bank Syariah Mandiri Cabang Yogyakarta (tidak termasuk layanan $S C O$ ).

Metode pengumpulan data di lokasi bank terhadap objek yang diteliti dengan cara : 1) Interview, yaitu melakukan tanya-jawab dengan pihak-pihak yang berkompeten di bank. Hal ini dilakukan untuk mendapatkan informasiinformasi yang diperlukan dalam penelitian. Pada penelitian ini penulis melakukan interview atau wawancara kepada pejabat bank yang dapat memberikan informasi mengenai penelitian ini. 2). Observasi, yaitu dengan melakukan pengamatan langsung ke berbagai kegiatan yang menjadi objek penelitian di bank. Hal ini dilakukan untuk memperoleh data yang diperlukan penulis termasuk data mengenai jumlah outlet masing-masing bank syariah, jumlah customer service, dan jumlah teller. Peneliti menggunakan metode observasi langsung untuk melihat secara langsung ke objek penelitian.

Waktu penelitian ini dilakukan selama 2 (dua) bulan dengan mengambil sampel periode waktu 3 (tiga) tahun yaitu tahun 2015, 2016, dan 2018.

\section{B. Pembahasan}

\section{Perkembangan Jumlah Outlet Kantor Bank Syariah di Yogyakarta dalam Era Digital Banking}


Berdasarkan hasil interview atau wawancara dengan sampel dalam penelitian, yaitu di Bank BNI Syariah KC Yogyakarta, Bank BRI Syariah KC Yogyakarta, Bank BTN KCS Yogyakarta, dan Bank Syariah Mandiri KC Yogyakarta. Secara garis besar adanya digital banking di perbankan syariah belum mengakibatkan perbankan syariah di Yogyakarta mengurangi outlet kantornya. Bank tersebut hanya melakukan pemetaan wilayah yaitu dengan merelokasi outlet kantor agar semua nasabah bisa dengan mudah menjangkau layanan.Seperti yang dilakukan oleh Bank BNI Syariah dan Bank Syariah Mandiri pada tahun 2018 yaitu dengan melakukan relokasi kantornya. Selama tahun penelitian yaitu dari tahun 2015 sampai tahun 2018, dalam Rencana Bisnis Bank (RBB) keempat bank yang dijadikan sampel penelitian sudah tidak melakukan perencanaan pembukaan outlet baru. Layanan digital banking saat ini masih terbatas pada layanan atm, cdm, sms banking, phone banking, mobile banking, dan internet banking. Belum bisa melayani pembukaan rekening maupun pengajuan pembiayaan secara online.

Layanan syariah channeling outlet bank konvensional di Yogyakarta untuk saat ini masih melayani transaksi di teller. Untuk pembukaan rekening masih bisa dilakukan di Bank Konvensional, kecuali di Bank BNI tidak bisa melakukan pembukaan rekening Bank BNI Syariah.

\section{Tabel 1}

Perkembangan jumlah outlet kantor bank syariah di Yogyakarta Th 2015-2018

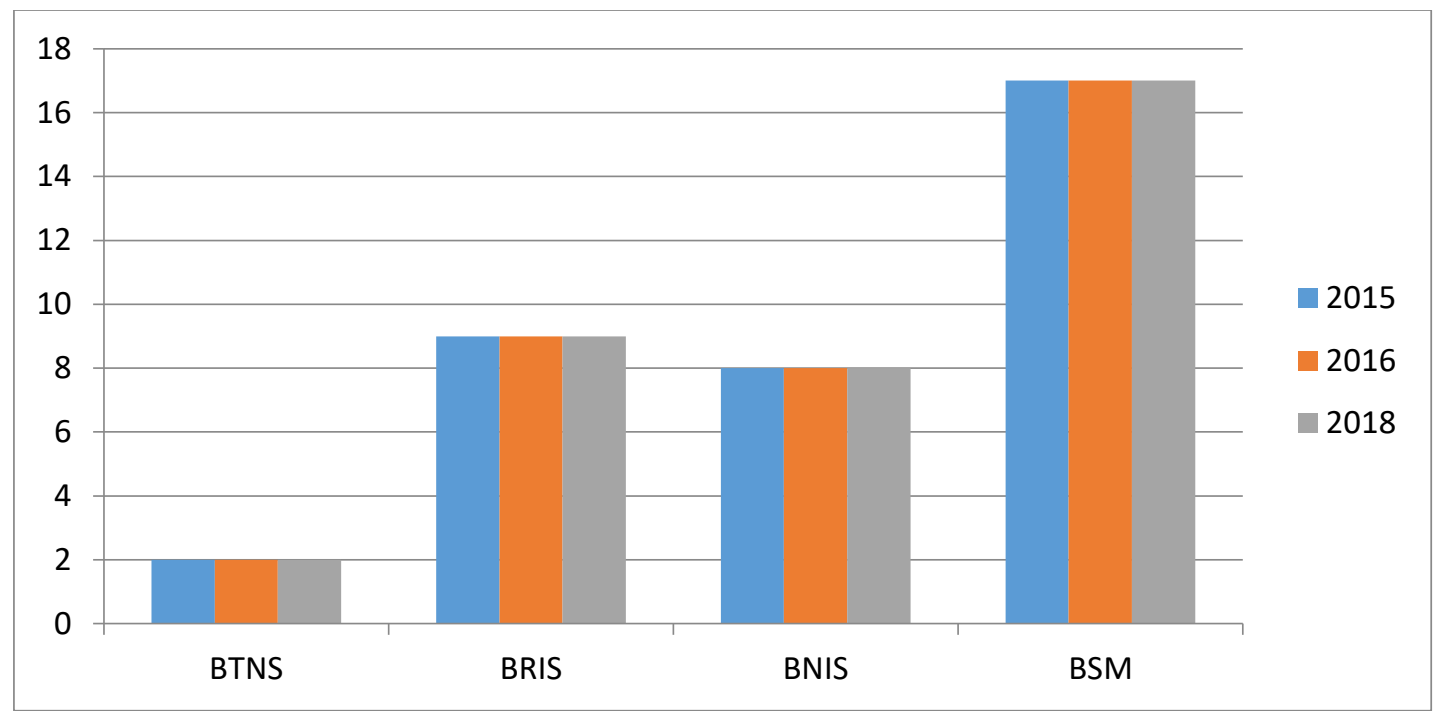

1. Bank BNI Syariah Kantor Cabang Yogyakarta 
Tahun 2015 jumlah outlet kantor Bank BNI Syariah Kantor Cabang Yogyakarta sebanyak 8 kantor. Hingga tahun 2018 jumlah outlet kantor yang dimiliki tetap sama. Hanya saja pada tahun 2018 ada relokasi dari Kantor Kas RS Mata Dr Yap direlokasi ke Kantor Kas Sleman dikarenakan untuk memeratakan sebaran outlet kantor, karena wilayah Kantor Kas RS Mata Dr Yap berdekatan dengan KCP Bulaksumur yang jaraknya tidak sampai 1 (satu) kilometer. Menurut Arif, Operational Manager Bank BNI Syariah Yogyakarta, dalam 3 (tiga) tahun terakhir tidak lagi melakukan penambahan jumlah outlet kantor.Wilayah atau daerah yang belum ada outlet kantornya diatasi dengan menempatkan marketing di Kantor Bank BNI Konvensional atau dengan sistem jemput nasabah. Untuk layanan sco oleh Bank BNI Konvensional hanya sebatas transaksi layanan di teller dan tidak bisa melakukan pembukaan rekening.

\section{Bank BRI Syariah Kantor Cabang Yogyakarta}

Tahun 2015 hingga tahun 2018 jumlah outlet kantor Bank BRI Syariah Kantor Cabang Yogyakarta sebanyak 9 kantor. Selama kurun waktu tersebut tidak ada penutupan kantor, relokasi kantor, maupun penambahan kantor baru. Menurut Kurniawan, Branch Manager Bank BRIS Yogyakarta, layanan syariah channeling outlet bisa dilakukan di Bank BRI Konvensional sehingga nasabah yang ingin membuka rekening Bank BRI Syariah bisa dilakukan di Cabang Konvensional. Hal ini sangat membantu penambahan jumlah nasabah Bank BRI Syariah yang ingin membuka rekening sekaligus layanan transaksi keuangan melalui teller.

Transaksi layanan digital banking di Bank BRI Syariah untuk saat ini meliputi layanan atm, cdm, sms banking, phone banking, mobile banking, dan internet banking. Sama dengan Bank BNI Syariah, di Bank BRI Syariah belum bisa melayani pembukaan rekening secara online.

\section{Bank BTN Kantor Cabang Syariah Yogyakarta}

Tahun 2015 hingga tahun 2018 jumlah outlet kantor UUS Bank BTN Kantor Cabang Syariah Yogyakarta sebanyak 2 kantor. Selama kurun waktu tersebut tidak ada penutupan kantor, relokasi kantor, maupun 
penambahan kantor baru. Menurut Slamet Wahyudi, Branch Manager Bank BTN KC Syariah Yogyakarta, layanan syariah channeling outlet bisa dilakukan di Bank BTN Konvensional yaitu di KCU Sudirman, KCP Nogotirto Godean, dan KCP Bantul sehingga nasabah yang ingin membuka rekening Bank BTNSyariah bisa dilakukan di Cabang Konvensional tersebut. Untuk outlet kantor konvensional yang lainnya belum bisa dilakukan pembukaan rekening. Sedangkan untuk layanan transaksi teller bisa dilakukan di semua outlet Kantor Bank BTN Konvensional.

Transaksi layanan digital banking di Bank BTN Syariah untuk saat ini meliputi layanan atm, sms banking, phone banking, mobile banking, dan internet banking. Untuk pembukaan rekening secara online di Bank BTN Syariah juga belum bisa dilayani.

\section{Bank Syariah Mandiri Kantor Cabang Yogyakarta}

Tahun 2015 sampai tahun 2018 jumlah outlet kantor Bank Syariah Mandiri Kantor Cabang Yogyakarta sebanyak 17 kantor termasuk Payment Point didalamnya. Tahun 2018 ada relokasi 2 (dua) kantor dari Kantor Cabang Utama yang semula di Jl. C Simanjuntak pindah ke Jl. Sudirman dikarenakan telah memiliki gedung sendiri. Kantor Kas Bantul direlokasi ke Kantor Kas UGM di Komplek RS Sardjito dikarenakan untuk memeratakan sebaran outlet kantor, karena wilayah Bantul dicover oleh KCP Bantul. Menurut Khoerul Wajid, Branch Manager, dalam 3 (tiga) tahun terakhir Bank Syariah Mandiri Yogyakarta tidak melakukan penambahan jumlah outlet kantor. Bank Syariah Mandiri Yogyakarta juga tidak melakukan pengurangan jumlah outlet kantornya, karena untuk mengantisipasi nasabah yang hendak bertransaksi ke kantor. Layanan syariah channeling outletdi Bank Mandiri untuk pembukaan rekening tidak bisa dilakukan, namun untuk layanan penarikan, penyetoran, dan kiriman uang bisa dilakukan di Bank Mandiri Konvensional.

\section{Perkembangan Kebutuhan Tenaga Frontliners Bank Syariah di Yogyakarta dalam Era Digital Banking}


Berdasarkan hasil interview atau wawancara dengan sampel dalam penelitian adalah Bank Syariah tidak melakukan rekruitment terhadap tenaga frontliners (teller dan customer service) sejak tahun 2015. Kebutuhan tenaga frontliners diambilkan dari back office atau unit lain yang personelnya dikurangi akibat adanya efisiensi. Namun bank syariah bukan berarti tidak melakukan penerimaan pegawai (recruitment). Bank syariah banyak melakukan pembukaan lowongan pekerjaan untuk posisi marketing mulai dengan status tenaga outsourching sampai tenaga asisten. Tenaga teller tidak lagi dibutuhkan karena dengan adanya digital banking transaksi nasabah sudah mulai beralih ke layanan digital yang tidak perlu harus antri lama dan lebih memudahkan nasabah dalam segala hal. Namun bank syariah dalam aktivitas bisnisnya tetap ditarget oleh manajemen untuk mencapai jumlah rekening baru (number of account). Sehingga mereka lebih membutuhkan tenaga marketing dibanding frontliners untuk mencapai target dari manajemen.

\section{Tabel 2}

Perkembangan jumlah CSkantor bank syariah di Yogyakarta Th 2015-2018

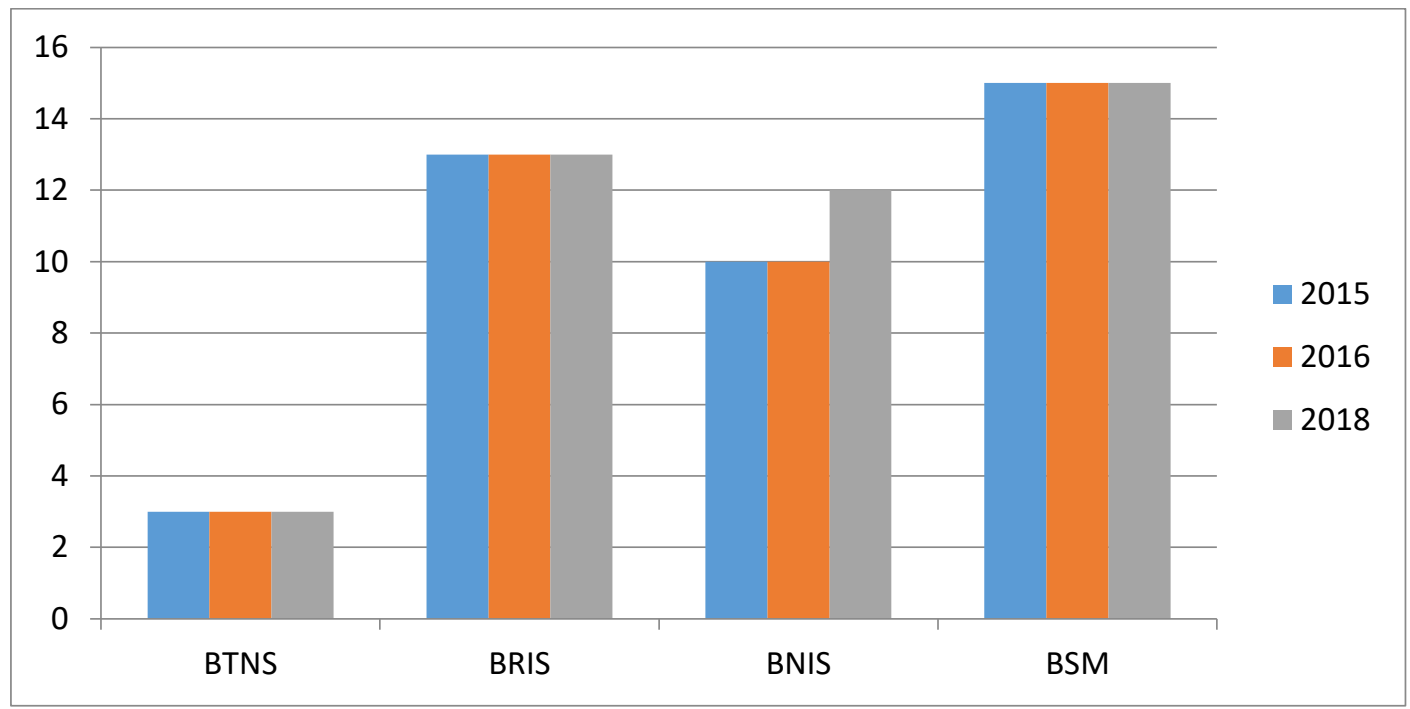

Tabel 3

Perkembangan jumlah Teller kantor bank syariah di Yogyakarta Th 2015-2018 


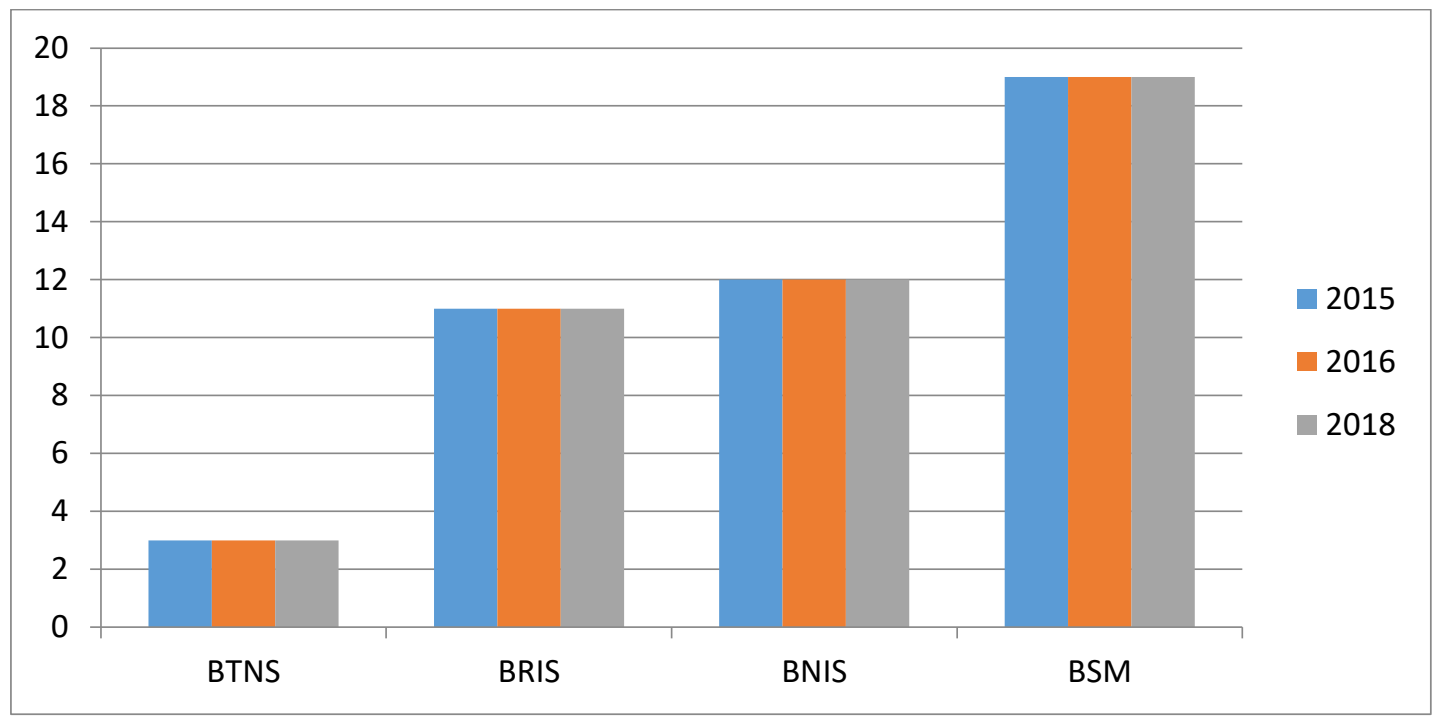

\section{Bank BNI Syariah Kantor Cabang Yogyakarta}

Bank BNI Syariah Kantor Cabang Yogyakartadari tahun 2015 sampai 2018memiliki 12 teller yang ditempatkan di 8 outlet kantor. Lokasi KCU jumlah teller ada 3 (tiga) dikarenakan ada 1 (satu) yang menjadi cash vault, menginput pembukuan transaksi internal baik realisasi pembiayaan maupun transaksi dari bagian keuangan dan umum. Sedangkan jumlah customer service hingga tahun 2018 ada 12 petugas. Pada tahun 2018 jumlah customer service di KCU dan KCP Godean ditambah 1 (satu) petugaskarena banyaknya penambahan tenaga marketingyang direkruit.

Transaksi layanan digital banking untuk saat ini meliputi atm, $c d m$, sms banking, phone banking, mobile banking, dan internet banking. Belum bisa melayani pembukaan rekening secara online. Perkembangan layanan digital perbankan menurut Arif, Operational Manager dampak yang paling terlihat adalah transaksi teller yang mengalami penurunan jumlah penarikan dan kiriman uang (antar cabang dan antar bank). Sedangkan untuk penyetoran di teller ada penurunan, tetapi tidak sebanyak penarikan dan kiriman uang antar cabang ataupun antar bank. Nasabah saat ini ada yang masih bertransaksi melalui teller karena adanya batasan limit transaksi layanan digital dan nasabah lebih nyaman datang ke kantor bank. 
Penurunan transaksi nasabah tidak membuat manajemen melakukan pengurangan pegawai untuk posisi frontliners, karena komposisi sudah pas dan jika dilakukan pengurangan dapat menimbulkan komplain nasabah. Saat ini bank justru melakukan penambahan tenaga marketing untuk mempercepat pencapaian target manajemen, sehingga menjadikan load pekerjaan customer service untuk melakukan pembukaan rekening hasil pencapaian dari marketing menjadi bertambah.

\section{Bank BRI Syariah Kantor Cabang Yogyakarta}

Jumlah teller Bank BRI Syariah Kantor Cabang Yogyakarta dari tahun 2015 sampai 2018sebanyak 11 petugas, sedangkan customer service sebanyak 13 petugas. Di beberapa outlet kantor ada yang jumlah customer service sebanyak 2 (dua) orang dan ada yang jumlah tellernya sebanyak 2 (dua) orang. Hal ini menyesuaikan banyaknya pekerjaan di tiap-tiap outlet.

Perkembangan layanan digital perbankan menurut Kurniawan, Branch Manageryang paling terlihat adalah transaksi melalui teller. Transaksi teller saat ini mengalami penurunan untuk transaksi penarikan dan kiriman uang (antar cabang dan antar bank), sedangkan untuk penyetoran melalui teller ada penurunan, tetapi jumlahnya tidak sebanyak penarikan. Selama tahun penelitian manajemen Bank BRI Syariah Yogyakarta tidak mengurangi jumlah petugas frontliners namun juga tidak melakukan pembukaan lowongan pekerjaan untuk posisi frontliners. Lowongan pekerjaan yang dibuka adalah tenaga marketing.

\section{Bank BTN Kantor Cabang Syariah Yogyakarta}

Jumlah teller Bank BTN Kantor Cabang Syariah Yogyakarta dari tahun 2015 sampai 2018 sebanyak 3 petugas, sedangkan customer service sebanyak 3 petugas. Perkembangan layanan digital perbankan menurut Slamet Wahyudi, Branch Manageryang paling terlihat adalah transaksi melalui teller. Transaksi teller saat ini mengalami penurunan untuk transaksi penarikan dan kiriman uang (antar cabang dan antar bank). Sedangkan untuk penyetoran melalui teller ada penurunan, tetapi jumlahnya tidak sebanyak penarikan dan kiriman uang antar cabang ataupun antar bank. Selama tahun penelitian manajemen Bank BTN 
Syariah Yogyakarta tidak melakukan pengurangan jumlah petugas frontliners (customer service dan teller), karena komposisi tersebut sudah jumlah minimum petugas.Bank BTN Syariah Yogyakarta sejak tahun 2015tidak melakukan pembukaan lowongan pekerjaan untuk posisi frontliners. Lowongan pekerjaan yang dibuka adalah tenaga marketing untuk membantu cabang mencapai target yang telah ditetapkan oleh manajemen.

\section{Bank Syariah Mandiri Kantor Cabang Yogyakarta}

Bank Syariah Mandiri Kantor Cabang Yogyakarta dari tahun 2015 sampai 2018memiliki petugas customer service sebanyak 15 petugas, sedangkan teller sebanyak 19 petugas. Selama tahun penelitian manajemen Bank Syariah Mandiri Yogyakarta tidak melakukan pengurangan jumlah petugas frontliners (customer service dan teller), karena komposisi tersebut sudah jumlah minimum petugas.Bank Syariah Mandiri mengambil tenaga dari back office atau marketing jika ada posisi frontliners yang cuti ataupun resign.Lowongan pekerjaan untuk posisi frontlinres tidak dibuka untuk saat ini. Justru tenaga marketing (outsourching) yang saat ini banyak dibuka lowongan pekerjaannya.

\section{Kesimpulan}

Berdasarkan hasil penelitian ini, kami menyimpulkan beberapa hal yaitu :

1. Selama masa penelitian dengan adanya digitalisasi perbankan saat ini tidak ada penambahan ataupun penguranganoutlet atau kantor baru. Hanya terdapat relokasi outletkantor dikarenakan untuk meratakan pemetaan wilayah dan mempermudah nasabah bertransaksi ke bank syariah.

2. Kebutuhan frontliners untuk posisi teller tidak ada pengurangan ataupun penambahan petugas. Namun untuk posisi customer servicehanya Bank BNI Syariah yang melakukan penambahan tenaga kerja sebanyak 2 (dua) petugas. Alasan penambahan customer servicedikarenakan Bank BNI Syariah melakukan penambahan tenaga marketingsehingga untuk 
membantu pembukaan rekening dari nasabah-nasabah yang aplikasinya dibawa oleh marketing bisa dilakukan lebih cepat.

3. Lowongan pekerjaan di bank syariah dengan adanya digital bankingsaat ini yang dibutuhkan adalah tenaga marketing. Sedangkan lowongan untuk posisi customer service dan teller selama masa penelitian tidak terdapat pembukaan lowongan. Jika staf posisi frontliners kosong, maka manajemen merotasi staf lain (back office) atau marketinguntuk menempati posisi frontliners. 


\section{DAFTAR PUSTAKA}

Antonio,Muhammad Syafii, 2001, Bank Syariah Dari Teori Ke Praktik, Jakarta, Gema Insani.

Departemen Pendidikan Nasional, 2012, Kamus Besar Bahasa Indonesia, Jakarta, Balai Pustaka.

Happy Fajrian, 2018, Transformasi Perbankan Menuju Layanan Robotik, Majalah Infobank, Jakarta

Https://sikapiuangmu.ojk.go.id/layanan digital banking, Dikutip pada 20 Juni 2018

Kasmir, 2013, Bank dan Lembaga Keuangan Lainnya, Jakarta, Raja Grafindo Persada.

Krisna Wijaya, 2018, Digital Banking, Majalah Infobank, Jakarta

Moenir, H.A.S.2002, Manajemen Pelayanan Umum di Indonesia, Jakarta, PTBumi Aksara.

Otoritas Jasa Keuangan, 2016, Panduan Penyelenggaraan Digital Branch oleh Bank Umum, Jakarta.

Sugiyono, 2006, Metode Penelitian Kuantitatif Kualitatif dan R\&D, Alfabeta, Bandung.

Totok Budisantoso \& Sigit Triandaru, 2011, Bank dan Lembaga Keuangan Lain, Edisi 3, Jakarta, Salemba Empat.

Wirjoatmodjo, Kartika, 2018,Transformasi Digital Suatu Keniscayaan, Majalah Infobank, Jakarta 